\title{
NADPH-oxidising activity in lens and erythrocytes in diabetic and nondiabetic patients with cataract
}

\author{
M. JAMES C. CRABBE, ANTHONY J. BRON, C. ORDE PECKAR, \\ MICHAEL PETCHEY, HONG-HOI TING, AND JULIA HOWARD-WILLIAMS \\ From the Nuffield Laboratory of Ophthalmology, University of Oxford, Walton Street, Oxford OX2 6AW
}

SUMMARY Levels of lens aldose reductase, aldehyde dehydrogenase activity, and erythrocyte NADPH-oxidising (or glyceraldehyde reductase) activity were determined in 17 diabetic and 16 nondiabetic patients undergoing cataract extraction. Lens aldose reductase and aldehyde dehydrogenase activities were significantly lower in diabetics than in nondiabetics. Both enzymes showed significant inverse correlations with grouped $\mathrm{HbA1c}$ and fasting blood glucose levels. By contrast, erythrocyte NADPH-oxidising activity showed a significant positive correlation with grouped $\mathrm{HbA} 1 \mathrm{C}$. It is suggested that a direct effect of the glycaemic status on the lens enzymes is masked by a loss of enzymes secondary to the development of cataract. It is not yet possible to say whether erythrocyte NADPH-oxidising activity can be used to monitor aldose reductase activity in the lens or other tissues in clinical trials of aldose reductase inhibitors.

Aldose reductase, the first enzyme of the polyol pathway, is a monomer of about 37000 daltons which catalyses the reduction of sugars to sugar alcohols with a broad substrate specificity. ${ }^{1}$

In diabetes increased flux through the polyol pathway has been implicated in the development of diabetic complications in the lens, retina, and periphal nerves. ${ }^{12}$ Aldose reductase inhibitors have been found to prevent cataract in the diabetic rat and to improve nerve conduction velocity. ${ }^{3}$ Commercial aldose reductase inhibitors are undergoing clinical trials, and their value in the prevention of cataract, peripheral neuropathy, and retinopathy is being studied. There is a need to monitor the effect of such inhibitors on enzyme activity in these target organs, but the impossibility of sampling such tissues makes an indirect technique attractive.

We have described an NADPH-oxidising activity in human erythrocytes which uses DL-glyceraldehyde as substrate (this has been referred to previously as glyceraldehyde reductase or glyceraldehyde-reducing activity), which is similar to aldose reductase (E.C.1.1.1.21) and whose mean levels are raised in diabetic retinopathy and cataract. ${ }^{4}$ In this study the relationship between erythrocyte NADPH-oxidising activity and lens aldose reductase activity is examined

Correspondence to Dr M. J. C. Crabbe. in diabetic and nondiabetic patients undergoing cataract extraction.

While lens aldose reductase catalyses the reduction of aldehydes to alcohols, another enzyme, aldehyde dehydrogenase (E.C.1.2.1.3.), catalyses the oxidation of aldehydes to acids. ${ }^{5}$ In the lens, aldehyde dehydrogenases may remove toxic aldehydes which otherwise could bind to lens proteins, causing conformational changes and subsequent cataract formation. The activity of this enzyme was also examined in the present study.

\section{Subjects and methods}

Thirty-three patients admitted to the Oxford Eye Hospital for cataract surgery were studied. There were 18 diabetic ( $11 \mathrm{M}$ and $7 \mathrm{~F}$ ) and 16 nondiabetic $(10 \mathrm{M}$ and $6 \mathrm{~F}$ ) patients. Their mean age was $70 \cdot 6$ years, SD 10.4 (diabetic) and 68.7 years, SD 10.6 (nondiabetic).

Each patient was given a study code on recruitment to the study. Patients underwent routine clinical assessment preoperatively, and the cataract status (mature, immature) and class (e.g., nuclear, subcapsular, spoke, etc) were noted. Postoperatively retinopathy was graded as follows: Background, minimal, $\leq 5$ microaneurisms; mild to moderate; microaneurisms, haemorrhages, and exudates; 
severe: extensive background \pm cotton wool spots/sclerosed vessels; proliferative; peripheral or disc new vessels. Extracted lenses were placed in lens pots and transferred to the laboratory. Lenses were divided in the midsagittal plane and enzyme studies performed on half-lens samples. The other half-lens sample was frozen at $-30^{\circ} \mathrm{C}$ for future studies of lens crystallins and capsule.

Biochemical findings were not available to the clinical observers at the time of clinical assessments. Biochemical studies were performed in ignorance of the diabetic status of the patients. For the comparison of erythrocyte NADPH-oxidising activity with $\mathrm{HbA} 1 \mathrm{c}$ levels the results of studies on 30 diabetics and 3 normal subjects were added to those of the present study.

Enzyme assays. Erythrocyte NADPH-oxidising activity, lens aldose reductase, and lens aldehyde dehydrogenase were assayed as described previously. ${ }^{467}$ Statistical and kinetic methods were as described previously. ${ }^{5}$

Human lens DNA. This was assayed as described previously. $^{8}$

\section{Results}

Diabetic patients had significantly higher HbAlc levels $(10 \cdot 7 \%$, SD $2 \cdot 36, n=16, p<0.001)$ and fasting blood glucose levels $(10 \cdot 3 \mathrm{mM}, \mathrm{SD} 4 \cdot 3, \mathrm{n}=17$, $\mathrm{p}<0.001)$ than nondiabetic patients $(6 \cdot 64$, SD $1 \cdot 16$, $\mathrm{n}=12$, and $5 \cdot 16 \mathrm{mM}, \mathrm{SD} \pm 0.92, \mathrm{n}=10$ ). There was a significant positive correlation between $\mathrm{HbAlc}$ and fasting blood glucose levels $(r=0.9)$ regardless of group.

Lens aldose reductase and aldehyde dehydrogenase activities were significantly lower in diabetic than in nondiabetic lenses $(2 \cdot 5$-fold and $3 \cdot 3-$ fold, $\mathrm{p}<0.001$ and $<0.05$ respectively). Mean lens aldehyde dehydrogenase activity was $30 \%$ lower in tablet-treated diabetics than in insulin-treated diabetics or those controlled on diet alone (Table 1).

Although mean levels of erythrocyte NADPH-

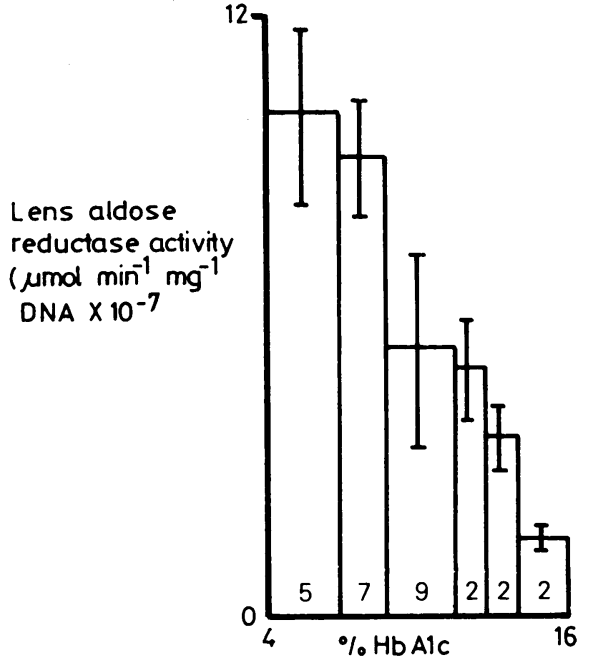

Fig. 1 Relationship between lens aldose reductase activity and $\mathrm{HbAlc}$ level in 27 patients undergoing cataract extractions: $r=0.99, p<0.001$ for slope. Numbers refer to number of patients in each section.

oxidising activity were not significantly different between diabetic and nondiabetic patients, those diabetics with retinopathy had a higher mean red cell activity than those without, which supports previous findings. Diabetics with retinopathy had a 35\% lower mean level of lens aldose reductase.

There was a significant negative correlation between lens aldose reductase and HbAlc levels as shown in Fig. $1(r=0.99, p<0.001)$. A similar negative correlation was found for lens aldehyde dehydrogenase $(r=0 \cdot 81, p<0 \cdot 05)$. Erythrocyte NADPHoxidising activity showed a significant positive correlation with $\mathrm{HbA} 1 \mathrm{c}(\mathrm{r}=0.91, \mathrm{p}<0 \cdot 02$, for a total of 69 diabetic and nondiabetic patients attending the Oxford Eye Hospital) (Fig. 2). There was no significant correlation between lens aldose reductase and erythrocyte NADPH-oxidising activity in the same patient $(p>0.05)$ or with sex of patient.

Table 1 Levels of lens aldose reductase, lens aldehyde dehydrogenase, and erythrocyte NADPH-oxidising activity in age-matched diabetic and nondiabetic patients undergoing cataract surgery

\begin{tabular}{|c|c|c|c|c|}
\hline & Age & $\begin{array}{l}\text { Lens aldose reductase } \\
\left(\mu \mathrm{mol} \mathrm{min}^{-1} \mathrm{ng}^{-1} \mathrm{DNA}\right) \\
\times 10^{-7}\end{array}$ & $\begin{array}{l}\text { Lens aldehyde dehydrogenase } \\
\left(\mu \mathrm{mol} \min ^{-1} \mathrm{ng}^{-1} \mathrm{DNA}\right) \\
\times 10^{-6}\end{array}$ & 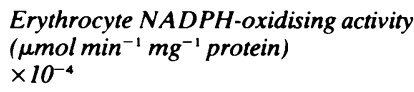 \\
\hline Diabetics & $\begin{array}{l}70 \cdot 6 \\
S D=10 \cdot 4\end{array}$ & $\begin{array}{l}4 \cdot 1 \\
\text { S.D.M. }=1 \cdot 2 \\
n=18\end{array}$ & $\begin{array}{l}3 \cdot 16 \\
\text { S.D.M. }=0 \cdot 84 \\
n=10\end{array}$ & $\begin{array}{l}5 \cdot 87 \\
\text { S.D.M. }=0 \cdot 45 \\
n=18\end{array}$ \\
\hline Nondiabetics & $\begin{array}{l}68 \cdot 7 \\
S D=10 \cdot 6\end{array}$ & $\begin{array}{l}10 \cdot 1 \\
\text { S.D.M. = } 1 \cdot 5 \\
n=14 \\
p<0 \cdot 001\end{array}$ & $\begin{array}{l}10 \cdot 46 \\
\text { S.D.M. }=2 \cdot 59 \\
n=15 \\
p<0 \cdot 05\end{array}$ & $\begin{array}{l}6 \cdot 23 \\
\text { S.D.M. }=0 \cdot 53 \\
n=15\end{array}$ \\
\hline
\end{tabular}




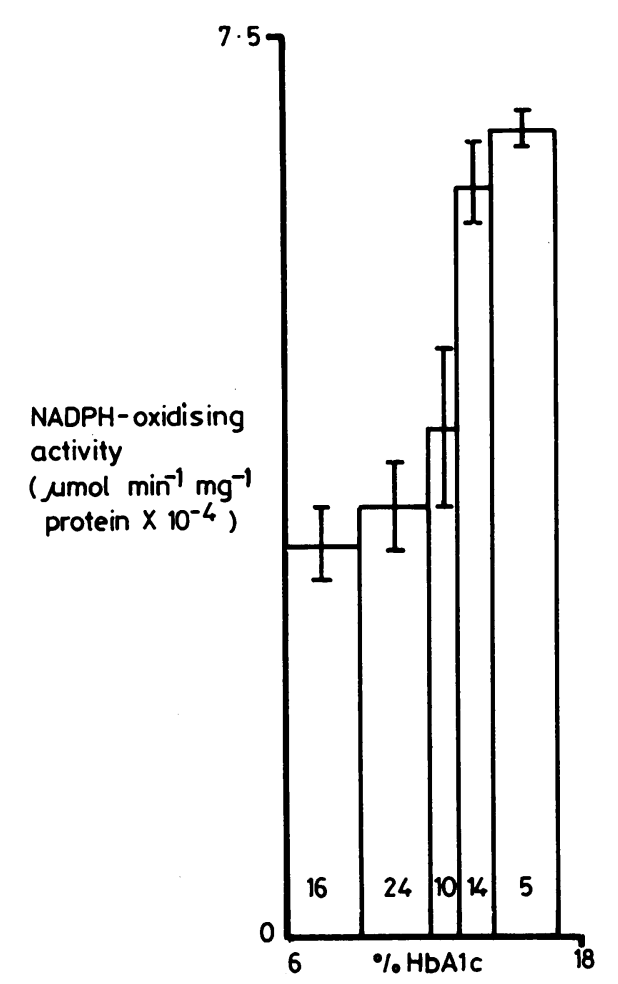

Fig. 2 Relationship between erythrocyte $N A D P H$-oxidising activity and HbAlc level in 69 diabetic and nondiabetic subjects; $r=0.9, p<0.02$ for slope. Numbers refer to number of patients in each section.

\section{Discussion}

In this study, as in others, higher HbAlc and fasting glucose levels were found in diabetic than nondiabetic patients, and there was a positive correlation between their levels. As in a previous study, ${ }^{4}$ erythrocyte NADPH-oxidising activity showed a positive correlation with $\mathrm{HbAlc}$ levels $(r=0.91$, $\mathrm{p}<0.02$ ), but levels of NADPH-oxidising activity were not significantly different between diabetic and nondiabetic patients. (This may reflect the fact that 6 of the diabetic patients had mild diabetes and were treated with diet alone.)

It was of particular interest to know whether lens aldose reductase behaved similarly to NADPHoxidising activity with respect to glycaemic control. In a previous study it was shown that diabetics with retinopathy or with cataract have a higher red-cell reducing activity than diabetics without. In this study, however, lens aldose reductase activity was found to correlate negatively with $\mathrm{HbA} 1 \mathrm{c}$ levels, and aldose reductase levels were lower in diabetic patients than nondiabetic. Not unexpectedly, therefore, no significant correlation was found between red cell glyceraldehyde reducing activity and lens aldose reductase levels. Jedziniak et al..$^{9}$ also found lower levels of aldose reductase activity in diabetic cataractous lenses than in nondiabetic cataractous lenses, but in animal studies of acute diabetic cataract raised levels of aldose reductase activity have been found.

There are a number of possible reasons why the erythrocyte and lens reducing enzymes behave differently in the present study with respect to glycaemic status. The glyceraldehyde-reducing enzyme of the red cell is similar to aldehyde reductase A (hexonate dehydrogenase) and is probably a different genetic product to aldose reductase $B$. Therefore there is no a-priori reason to expect them to behave in an identical fashion in response to altered substrate conditions. Moreover, with present methods the reducing activity measured in the red cell is due in part to glyceraldehyde reductase activity and in part to an oxidation of haemoglobin in the presence of glyceraldehyde. ${ }^{10}$ The rate of this oxidation is increased in the presence of raised levels of glycosylated haemoglobin, and this oxidation, which produces a spectral change at $340 \mathrm{~nm}$, may contribute a significant portion of the measured increase in rates of change of absorbance at high $\mathrm{HbAlc}$ levels.

Another factor which may explain the different relationship between lens aldose reductase and erythrocyte glyceraldehyde reducing activity to $\mathrm{HbA1c}$ levels may be the differing biological state of the 2 tissues at the time of study. The erythrocytes are intact, while the presence of cataract implies that a proportion of the cells of the lens are not. If the sorbitol pathway is central to the mechanism of cataract formation in diabetics, then just those cells (the lens epithelial cells and superficial lens fibre cells) which show the highest levels of aldose reductase activity in the normal lens will suffer first in cataractogenesis. Lowered levels of aldose reductase activity in the diabetic cataractous lens may therefore reflect a secondary loss of enzyme from lens cells following cellular damage, and is not comparable to activity levels measured in the red cell. An attempt to resolve this problem in the present study by relating aldose reductase levels to in-vitro cataract grade was not appropriate, since the grading system used refers only to events in the nucleus of the lens, where aldose reductase activity is very low. Future studies will employ a clinical cataract grading scheme which will identify changes in both the nucleus and cortex of the lens.

From these comments it will be seen that the value of using red-cell reducing activity as a guide to tissue (e.g., lens) aldose reductase activity in 
studies of aldose reductase inhibitors cannot be assessed in the present study. The effect of glycaemic status on aldose reductase activity in the noncataractous lens can come only from studies of fortuitously obtained normal human lens. Such studies are in progress.

Levels of lens aldehyde dehydrogenase activity parallel those of lens aldose reductase. Lens aldehyde dehydrogenase activity was lower in diabetics than nondiabetics and was negatively correlated with HbA1c levels. As there is no general hypothesis linking dehydrogenase activity to glycaemic status, it should be considered whether these lowered levels again are secondarily linked to a sorbitol-pathway mechanism of lens cell damage. However, of particular interest was the finding that lens aldehyde dehydrogenase activity was $30 \%$ lower in patients receiving oral hypoglycaemics than in insulin-treated diabetics. There is evidence both of an increase in reactive aldehyde groups in cataractous lens and that such groups will react with and bind to lens protein. The fall in dehydrogenase activity demonstrated in this study may reflect a disturbance of aldehyde detoxification in the lens, and it may be that it is susceptible to the action of inhibitors such as chlorpropamide, tolbutamide, or other potent inhibitors of the enzyme in vitro. No age- or duration- dependent effect on lens aldehyde dehydrogenase activity was found.

\section{References}

1 Crabbe MJC, Ting H-H, Basak Halder A. Aldehyde reductase and dehydrogenase, and their possible involvement in diabetes and cataract formation. In: Weiner $\mathrm{H}$, Wermuth $\mathrm{B}$, eds. Aldehyde reductases and dehydrogenases. New York: Alan Liss, $1982 ; 329-46$.

2 Pirie A, Van Heyningen R. The effect of diabetes on the content of sorbitol, glucose, fructose and inositol in the human lens. Exp Eye Res 1964; 3: 124-31.

3 Fukushi S, Merola LO, Kinoshita JH. Altering the course of cataracts in diabetic rats. Invest Ophthalmol Visual Sci 1980; 19: 313-5.

4 Crabbe MJC, Peckar CO, Basak Halder A, Cheng H. Erythrocyte glyceraldehyde reductase levels in diabetics with retinopathy and cataract. Lancet 1980; ii: 1268-70.

5 Ting $\mathrm{H}-\mathrm{H}$, Crabbe MJC. Ethanol, formaldehyde and lens proteins. Biochem Soc Trans 1982; 10: 412-3.

6 Ting H-H, Crabbe MJC. Purification of bovine lens aldehyde dehydrogenase. Biochem Soc Trans 1982; 10: 409.

7 Crabbe MJC, Basak Halder A. Kinetic behaviour under defined assay conditions for bovine lens aldose reductase. Clin Biochem 1979; 12: 281-3.

8 Kissane JM, Robbins EH. The fluorimetric measurement of deoxyribonucleic acid in animal tissues with specific reference to the central nervous system. J Biol Chem 1958 ; 233: 184-8.

9 Jedziniak JA, Chylack LT, Cheng H-M, Gillis MJ, Kalustian AA, Tung WH. The sorbitol pathway in the human lens. Invest Ophthalmol Visual Sci 1981; 20: 312-26.

10 Wolff SP, Crabbe MJC, Thornally PJ. The autoxidation of glyceraldehyde and other monosaccharides. Experientia in press. 